Check for updates

Cite this: RSC Adv., 2019, 9, 6452

\title{
Synthesis and properties of zeolite/N-doped porous carbon for the efficient removal of chemical oxygen demand and ammonia-nitrogen from aqueous solution
}

\author{
Guangzhi Xin, (D) a Min Wang, ${ }^{\mathrm{b}}$ Lin Chen, ${ }^{a}$ Yuzhou Zhang, ${ }^{\mathrm{a}}$ Meicheng Wang, ${ }^{\mathrm{a}}$ \\ Wenju Jiang ${ }^{a}$ and Yao Chen ${ }^{\star a}$
}

A novel adsorbent zeolite/ $\mathrm{N}$-doped porous activated carbon (ZAC) was prepared by the synthesis of zeolite and mesoporous carbon to remove ammonia nitrogen $\left(\mathrm{NH}_{4}{ }^{+}-\mathrm{N}\right)$ and chemical oxygen demand (COD) from aqueous solution. The impacts of adhesives, molding pressure, synthetic temperature and ratio on ZAC preparation were investigated. The prepared adsorbent was characterized by BET surface area measurement, scanning electron microscopy and X-ray diffraction. The adsorption kinetics was better depicted by the pseudo-second-order model than the pseudo-first-order model and the isotherm fitted well with the Langmuir model. The adsorption process was endothermic, spontaneous and favorable according to thermodynamic data. The adsorbent has much potential in the simultaneous removal of

COD and $\mathrm{NH}_{4}{ }^{+}-\mathrm{N}$ from wastewater.

Received 26th October 2018

Accepted 11th February 2019

DOI: $10.1039 / \mathrm{c} 8 \mathrm{ra0} 8800 \mathrm{~d}$

rsc.li/rsc-advances

\section{Introduction}

Pollutants from wastewater such as organics, dyes, ${ }^{1,2}$ heavy metals, ${ }^{3}$ nitrogen and phosphorus ${ }^{4}$ have made a serious impact on human beings with the surge of industrialization, urbanization, and scientific and technological innovation. ${ }^{5}$ According to the China Environmental Statistics Annual Report (2015), 2.24 $\times 10^{7}$ tons of chemical oxygen demand (COD) and $2.30 \times 10^{6}$ tons of ammonia nitrogen $\left(\mathrm{NH}_{4}{ }^{+}-\mathrm{N}\right)$ were produced and discharged into wastewaters. As is widely known, large amount of nitrogen is one of the major factors for eutrophication in water bodies, and causes hypoxia or death to hydrophytes and aquatic animals due to its inhibition of oxygen transportation with the surge of algae. In addition, it is also very harmful to water plumbing systems and devices during sewage reuse. ${ }^{6-8}$

Traditionally, techniques and methods such as biodegradation, advanced oxidation, catalytic oxidation, and photocatalysis are employed in COD and $\mathrm{NH}_{4}{ }^{+}-\mathrm{N}$ removal, ${ }^{9-13}$ which are usually time-consuming and high-cost. Adsorption is a conventional and widely used method in low-concentration pollution treatment due to its simple operation, low-cost and high adsorption capacity. Each adsorbent has its own advantages and disadvantages; however, it would negate their effects in some extensive application. For example, chitosan shows high adsorption capacities to reactive and basic dyes due to its

${ }^{a}$ College of Architecture and Environment, Sichuan University, Chengdu 610065, China. E-mail: chenyao@scu.edu.cn; Fax: +86-28-8540-5613; Tel: +86-28-8540-3016 ${ }^{b}$ Southwest Oil and Gas Branch Co., SINOPEC, Chengdu 610065, China high content of amino and hydroxy functional groups, but it will be limited by formation of gels under low $\mathrm{pH}$ values. Thus, it is important to develop a composite absorbent to integrate precursors' predominance and compensate for their deficiencies. M. Hasan, et al. ${ }^{14}$ used epichlorohydrin (ECH) as a cross-linking agent to obtain crosslinked chitosan/oil palm composite beads (CC/OPA) for Reactive Blue 19 removal, which improved better stability and mechanical strength of the prepared adsorbent in acid medium. It was also reported that chitosan-g-poly(acrylic acid)/rice husk ash hydrogel composite showed good removal efficiency in high initial methylene blue (MB) concentration. ${ }^{15}$

Natural materials such as zeolites show considerable adsorption capacities on $\mathrm{NH}_{4}{ }^{+}-\mathrm{N}$ from aqueous solutions mainly by ion-exchange. ${ }^{16,17}$ Activated carbon (AC), an effective adsorption material in the removal of pollutants such as dyes and heavy metals from wastewater, gained significant interests because of its high specific surface area and stability of chemical properties. Abundant investigations on AC were focused on the cheap and easy-get precursors such as fly ash, ${ }^{18}$ activated sludge, ${ }^{19}$ pine-fruit shell, ${ }^{20}$ saw dust, ${ }^{21}$ hevea seed coat, ${ }^{22}$ palm kernel shell, ${ }^{1,23}$ oil palm, ${ }^{24}$ waste tire rubber, ${ }^{25}$ bamboo. ${ }^{26}$ Zeolite/activated carbon composite was aimed to acquire the cooperative and bi-functional properties on simultaneous removal of COD and $\mathrm{NH}_{4}{ }^{+}-\mathrm{N}$. W. A. Khanday et al. attempted to convert oil palm ash and unburnt carbon into a new composite for removing $\mathrm{MB}$ from solutions, of which the $\mathrm{MB}$ adsorption capacity value was $138.15 \mathrm{mg} \mathrm{g}^{-1}\left(C_{0}=400 \mathrm{mg} \mathrm{L}^{-1}\right)$ at $30^{\circ} \mathrm{C}$ and was superior to previous studies..$^{24}$ It was investigated that an 
activated carbon-zeolite composite for removing $\mathrm{MB}$ and $\mathrm{NH}_{4}{ }^{+}$ $\mathrm{N}$ was prepared with $\mathrm{AC}$ and kaolin by hydrothermal synthetic method. ${ }^{27}$ However, in situ synthetic method of composite absorbent is limited in environmental application due to its complicated preparation and operation. A. A. Halim et al. produced one carbon-mineral composite adsorbent with ordinary portland cement (OPC) to degrade $\mathrm{COD}$ and $\mathrm{NH}_{4}{ }^{+}-\mathrm{N}$ from landfill leachate. ${ }^{28}$ The $\mathrm{COD}$ and $\mathrm{NH}_{4}{ }^{+}-\mathrm{N}$ adsorption capacity were $22.99 \mathrm{mg} \mathrm{g}^{-1}\left(C_{0}=2338.29 \mathrm{mg} \mathrm{L}^{-1}\right)$ and $24.39 \mathrm{mg} \mathrm{g}^{-1}\left(C_{0}\right.$ $\left.=1890.95 \mathrm{mg} \mathrm{L}^{-1}\right)$, respectively. A certain amount of adhesive can be applied to improve mechanical strength of powdery absorbents in favor of engineering application and transportation. ${ }^{29} \mathrm{~A}$ small mass of adhesives was added in raw materials to acquire a cheap and easy-prepared composite absorbent, which had little impact on original adsorption capacity.

The main objective of this investigation was to explore the synthetic method of zeolite/N-doped porous activated carbon (ZAC) and to optimize operation of this novel composite absorbent in simultaneous removal of COD and $\mathrm{NH}_{4}{ }^{+} \mathrm{N}$ from aqueous solutions. It is worthy retaining properties of both matrixes in preparation of a new composite absorbent. The composite ZAC was prepared by cementation, extrusion and calcination, successively. The effects of operational parameters, i.e., adhesive, molding pressure, and synthetic temperature were examined. Kinetics, isotherm and thermodynamics models were studied to further understand the adsorption process of ZAC.

\section{Materials and methods}

\section{Raw materials}

Wood-derived activated carbon NAC (N-doped activated carbon) was obtained from our previous work, ${ }^{27}$ which derived from wood sawdust ( $43.1 \% \mathrm{C}, 5.3 \% \mathrm{H}, 0.1 \% \mathrm{~N}, 0.1 \% \mathrm{~S}$ and $51.4 \% \mathrm{O}$ ). Commercial zeolite $(\mathrm{Z})$ was purchased from Sinopharm Chemical Reagent Company ( $\left.\mathrm{CP}, \mathrm{Na}_{2} \mathrm{O} \cdot \mathrm{Al}_{2} \mathrm{O}_{3} \cdot x \mathrm{SiO}_{2} \cdot y \mathrm{H}_{2} \mathrm{O}\right)$, and rinsed several times with distilled water to remove impurity for further application. NAC and $Z$ were grinded and sieved to 200 mesh and dried in an oven $\left(105^{\circ} \mathrm{C}\right)$ for further utilization.

$\mathrm{MB}$ and ammonium chloride $\left(\mathrm{NH}_{4} \mathrm{Cl}\right)$ were dissolved in distilled water to prepare $\mathrm{COD}$ and $\mathrm{NH}_{4}{ }^{+}-\mathrm{N}$ stock solutions. Working solutions of certain concentration were prepared by consecutive dilution of the standard stock solution. All reagents and chemicals used were of analytical grade quality and obtained from Chron Chemicals.

\section{Preparation of the composite material}

$\mathrm{NAC}$ and $\mathrm{Z}$ were mixed with a mass ratio of $5: 5$ and a certain amount of adhesive was added and fully mixed to improve the compound's intensity and molding cohesiveness. After mixing, the composite was dried in an oven at a temperature of $105^{\circ} \mathrm{C}$ to ensure moisture content kept in the range of $30-50 \%$, and then extruded into cylinders with a diameter of $13 \mathrm{~mm}$ (powder compressing machine, SYP-15A). The extrudate was loaded in a quartzose reactor placed in a tube furnace $($ OTF-1200 $\times$ ). The synthesis was carried out by ramping the temperature from room temperature to $200{ }^{\circ} \mathrm{C}$ with a heating rate of $10^{\circ} \mathrm{C} \mathrm{min}{ }^{-1}$ and hold for $1 \mathrm{~h}$. After calcination and cooling down to room temperature, zeolite/N-doped porous activated carbon (ZAC) composite was obtained.

\section{Adsorption tests}

$0.05 \mathrm{~g}$ ZAC composite and $100 \mathrm{~mL}$ simulation wastewater with varying initial $\mathrm{COD}$ and $\mathrm{NH}_{4}{ }^{+}-\mathrm{N}$ concentrations were mixed in a series of Erlenmeyer flasks $(250 \mathrm{~mL})$ to carry out batch adsorption experiments. The adsorption isotherms were obtained by batch experiments at different temperatures $\left(15{ }^{\circ} \mathrm{C}\right.$, $25{ }^{\circ} \mathrm{C}$ and $\left.35{ }^{\circ} \mathrm{C}\right)$. The mixture was continuously shaken $(150$ rpm) in a temperature-controlled shaker for $3 \mathrm{~h}$ until equilibrium was reached. Then the adsorbent was filtered out to analyze $\mathrm{COD}$ and $\mathrm{NH}_{4}{ }^{+}-\mathrm{N}$ concentration of the residual. Adsorption kinetics was carried out at $25^{\circ} \mathrm{C}$ and the initial COD concentrations were $100-1600 \mathrm{mg} \mathrm{L}{ }^{-1}$, respectively. After predetermined time intervals, the adsorbent was filtered out to analyze the final concentration of the supernatant. The effects of adhesives, molding pressure and synthetic temperature on ZAC preparation were justified by adsorption experiments using $0.5 \mathrm{~g} \mathrm{~L}^{-1} \mathrm{ZAC}$ in a series of $100 \mathrm{~mL}$ solutions with a COD concentration of $500 \mathrm{mg} \mathrm{L}^{-1}$ and a series of $50 \mathrm{~mL}$ solutions with an $\mathrm{NH}_{4}{ }^{+}-\mathrm{N}$ concentration of $100 \mathrm{mg} \mathrm{L}^{-1}$, respectively.

The equilibrium adsorption amount, $q_{\mathrm{e}}\left(\mathrm{mg} \mathrm{g}^{-1}\right)$, is calculated by the following equation:

$$
q_{\mathrm{e}}=\frac{C_{0}-C_{\mathrm{e}}}{m} V
$$

where $C_{\mathrm{e}}\left(\mathrm{mg} \mathrm{L}^{-1}\right)$ and $C_{0}\left(\mathrm{mg} \mathrm{L}^{-1}\right)$ respectively represent the equilibrium and initial pollutant concentration, $m(\mathrm{~g})$ is the mass of ZAC composite adsorbent and $V(\mathrm{~L})$ is solution volume.

COD was analyzed by the potassium dichromate method and $\mathrm{NH}_{4}{ }^{+}-\mathrm{N}$ was analyzed by Nessler's reagent colorimetry method, ${ }^{30}$ using UV/visible double-beam spectrophotometer (5B-3C Lianhua Corporation, China).

The loss rate was utilized to describe the solidity and stability of the materials. The lower the loss rate, the more waterresistant and stable of the material (eqn (2)). In order to calculate the loss rate, a certain mass of absorbent was put in $50 \mathrm{~mL}$ deionized water and agitated in a flask at $150 \mathrm{rpm}$ in a temperature-controlled shaker for $0.5 \mathrm{~h}$. Then the absorbent was filtered and dried under $105{ }^{\circ} \mathrm{C}$ to constant weight.

$$
P=\frac{M_{0}-M_{1}}{M_{0}} \times 100 \%
$$

where $M_{0}(\mathrm{~g})$ and $M_{1}(\mathrm{~g})$ respectively represent the initial and end mass of the absorbent, $P$ is the loss rate.

All experiments were carried out in duplicate, and the average values were reported.

\section{Characterization}

The scanning electron microscope (SEM) of the composite were obtained to study the morphology and textural structure of the 
composite by JSM-7500F (JEOL, Japan), X-ray photoelectron spectroscopy (XPS) was performed on an AXIS Ultra DLD (KRATOS) spectrometer using $\mathrm{Al} \mathrm{K} \alpha$ radiation $(1486.6 \mathrm{eV})$ operated at an accelerating power of $150 \mathrm{~W}$.

$\mathrm{N}_{2}$ adsorption-desorption method at $77 \mathrm{~K}$ was performed to evaluate the surface physical properties of the composite, which were analyzed by ASAP 2460 (Micromeritics Corporation, USA)

The powder X-ray diffraction (XRD) pattern of the composite was recorded in the $2 \theta$ ranging between $10^{\circ}$ and $80^{\circ}$ and using X-Pert PRO MPD (PANalytical B. V. Holland) equipped with $\mathrm{Cu}$ $\mathrm{K} \alpha$ radiation $(\lambda=1.54056 \mathrm{~A})^{\circ}$ at $30 \mathrm{~mA}$ and $30 \mathrm{kV}$.

\section{Result and discussion}

\section{Synthesis}

Effect of adhesives. Several adhesives were used to enhance the aggregation and cohesiveness of the composite. Fig. 1 shows the effect of adhesives on preparation of ZAC. Sodium carboxymethylcellulose (CMC), polyvinyl alcohol (PVA) and sodium silicate were applied on ZAC preparation under $200{ }^{\circ} \mathrm{C}$ synthetic temperature for $1 \mathrm{~h}$ and extruded with a molding pressure of $8 \mathrm{MPa}$. As seen from Fig. 1c, sodium silicate is unnecessary in the production of the composite with a high loss rate. Though a good COD removal efficiency was achieved, there was little adhesive attraction among the adhesive and raw materials. Whereas, the loss rate of the composite with CMC and PVA were much lower than sodium silicate's as shown in Fig. 1, representing well adhesive attraction and cohesiveness among those materials. As seen from Fig. 1a and $b$, the more addition of adhesive, the worse removal efficiency of COD and $\mathrm{NH}_{4}{ }^{+}-\mathrm{N}$ on ZAC. This may be due to collapsing and blocking of holes by adhesives. The removal efficiency of COD and $\mathrm{NH}_{4}{ }^{+}-\mathrm{N}$ on ZAC with CMC was much superior to the one with PVA under same conditions, which showed CMC was an optimal adhesive in the composite production. There was no obvious change of the loss rate, and the removal efficiency of COD and $\mathrm{NH}_{4}{ }^{+}-\mathrm{N}$ was stable by increasing the proportion of CMC from $15 \%$ to $20 \%$ (Fig. 1a). Therefore, considering cost and adsorption capacity, modification with $15 \%$ CMC was favorable on ZAC preparation, in which $67.5 \%$ COD and $46.3 \% \mathrm{NH}_{4}{ }^{+}-\mathrm{N}$ removal efficiency could be reached.

Effect of molding pressure. An auto-powder compressing machine was utilized for ZAC to form small tablet $(\Phi 13 \mathrm{~mm})$ under a pressure range of 2-10 MPa. Fig. 2 shows the effect of molding pressure on preparation of ZAC for COD and $\mathrm{NH}_{4}{ }^{+}-\mathrm{N}$ removal under synthetic temperature $200{ }^{\circ} \mathrm{C}$ for $1 \mathrm{~h}$ with $15 \%$ CMC addition. As illustrated in Fig. 2, the removal efficiency for both $\mathrm{COD}$ and $\mathrm{NH}_{4}{ }^{+}-\mathrm{N}$ on ZAC were almost no change under various pressure, while the strength of the tablet was improved with augment of the pressure. To obtain high capacity of the composite material, extrusion pressure is a crucial factor during the synthetic process. Under a pressure of $8 \mathrm{MPa}$, the produced carbon was stable with only $2.39 \%$ loss rate and could get a COD and $\mathrm{NH}_{4}{ }^{+}-\mathrm{N}$ removal $c a .68 \%, 46 \%$, respectively.

Effect of synthetic temperature. The extruded tablets were placed in a tube furnace for calcination in the temperature range of $100-300{ }^{\circ} \mathrm{C}$ under $\mathrm{N}_{2}$ atmosphere $\left(200 \mathrm{~mL} \mathrm{~min}^{-1}\right)$. The effect of synthetic temperature on preparation of ZAC with $15 \%$ CMC addition under molding pressure $8 \mathrm{MPa}$ was discussed and the result was presented in Fig. 3. Although the loss rate of ZAC was much lower under high temperature, the removal efficiency of COD and $\mathrm{NH}_{4}{ }^{+}-\mathrm{N}$ was significantly decreased with temperature rising. It may be attributed to collapse and blocking of holes under high temperature. $200{ }^{\circ} \mathrm{C}$ was feasible for ZAC preparation, under which $67 \%$ COD and $49 \% \mathrm{NH}_{4}{ }^{+}-\mathrm{N}$ removal efficiency could be achieved.

Effect of synthetic ratio. The effect of synthetic ratio (Z/NAC) on preparation of ZAC for COD and $\mathrm{NH}_{4}{ }^{+}-\mathrm{N}$ removal was studied with a weight proportion (1:9 to $9: 1)$ of two raw materials. As shown in Fig. 4, pure NAC showed perfect COD removal rate, which was related to its high surface area and mesopore. With larger amount of NAC, the produced ZAC was more favorable on COD removal. However, poor $\mathrm{NH}_{4}{ }^{+}-\mathrm{N}$ adsorption capacity was also observed in pure NAC due to its non-polar surface. It was reported that $\mathrm{NH}_{4}^{+}$has better ion-exchange capacity than $\mathrm{Na}^{+}$, aqueous ammonium can be exchanged by $\mathrm{Na}^{+}$from $\mathrm{Na}$-zeolites such as clinoptilolite ${ }^{31}$ and mordenite. ${ }^{32}$ The adsorption capacity of $\mathrm{NH}_{4}{ }^{+}-\mathrm{N}$ on ZAC with larger content of zeolite was enhanced. Having more zeolite, the ZAC production was much better for $\mathrm{NH}_{4}{ }^{+}-\mathrm{N}$ adsorption. The efficient and simultaneous removal of both COD and $\mathrm{NH}_{4}{ }^{+}-\mathrm{N}$ could be achieved by properly adjusting the proportion of two raw materials in ZAC. At a zeolite/ NAC mass ratio of $5: 5$, a relatively high removal efficiency for both COD and $\mathrm{NH}_{4}{ }^{+}-\mathrm{N}$ was obtained.

\section{Adsorbent characterization}

$\mathrm{N}_{2}$ adsorption-desorption isotherm at $77 \mathrm{~K}$ and textural parameters of the composite ZAC (5:5) are listed in Table 1. As
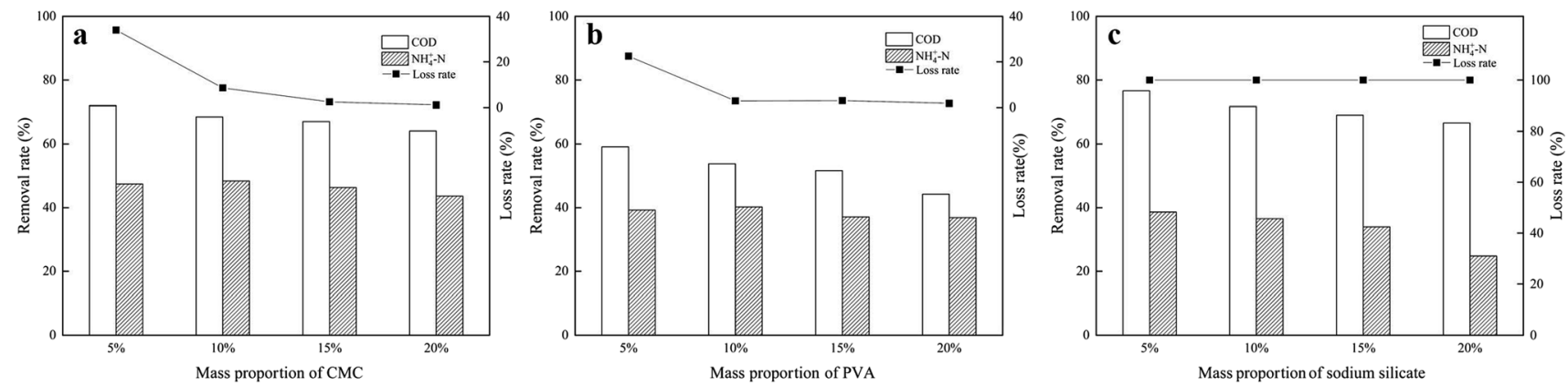

Fig. 1 Effect of adhesives on preparation of composite material (ZAC) for $\mathrm{COD}$ and $\mathrm{NH}_{4}{ }^{+}-\mathrm{N}$ removal. 


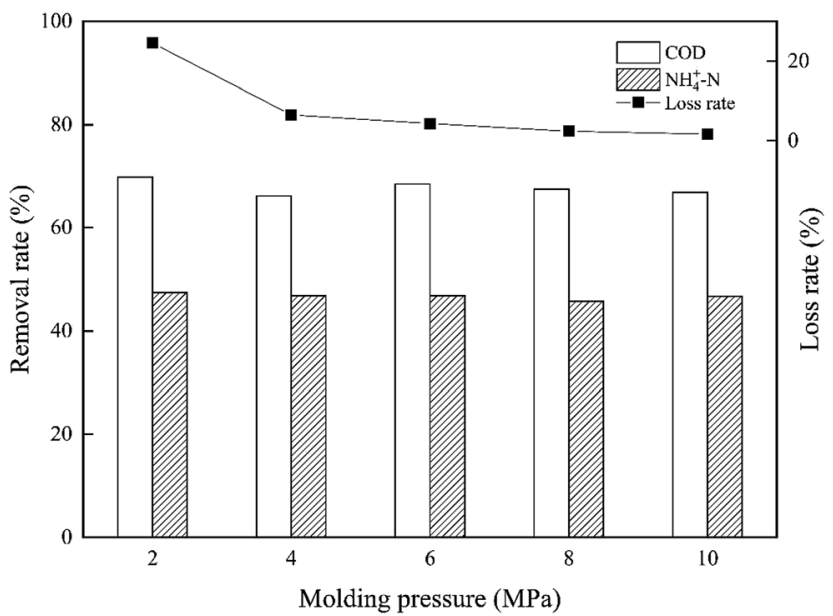

Fig. 2 Effect of molding pressure on preparation of composite material (ZAC) for $\mathrm{COD}$ and $\mathrm{NH}_{4}{ }^{+}-\mathrm{N}$ removal.

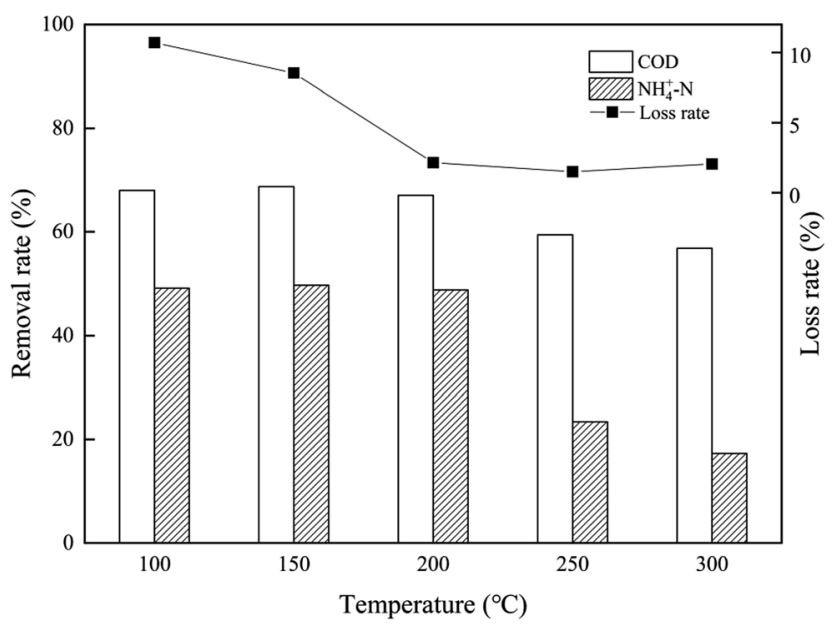

Fig. 3 Effect of synthetic temperature on preparation of composite material (ZAC) for COD and $\mathrm{NH}_{4}{ }^{+}-\mathrm{N}$ removal.

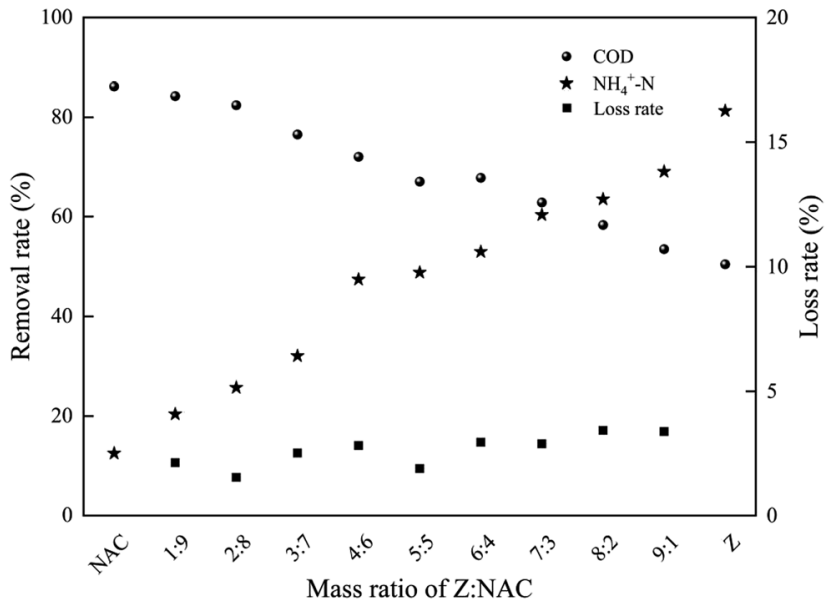

Fig. 4 Effect of synthetic ratio ( $Z$ : NAC) on preparation of composite material (ZAC) for COD and $\mathrm{NH}_{4}{ }^{+}-\mathrm{N}$ removal. it is shown in Table 1, there is barely microporous or mesoporous structure in zeolite and its BET surface area is a little low. The high removal efficiency of $\mathrm{NH}_{4}{ }^{+}-\mathrm{N}$ by zeolite is attributed to ion-exchange. Higher $S_{\mathrm{BET}}$ and micropore volume were observed in NAC, which gave rise to good COD adsorption capacity. However, NAC showed unsatisfactory adsorption to $\mathrm{NH}_{4}{ }^{+}-\mathrm{N}$ due to its nonpolar surface. The existence of mesopore was found in composite ZAC after material synthesis on the basis of isotherm calculation. The composite ZAC acquired simultaneous removal of COD and $\mathrm{NH}_{4}{ }^{+}-\mathrm{N}$ by combining the advantages of two raw materials, while it had lower surface area in comparison with NAC.

SEM picture of the composite ZAC $(1000 \times$ magnification $)$ is shown in Fig. 5. It can be observed that the ZAC surface represents clear granular morphology and the powder zeolite and NAC are cohesive by adhesive effect with the help of CMC. Moreover, there was $0.2 \% \mathrm{~N}$ in composite ZAC as shown by XPS results, which was stemmed from nitrogenous NAC; the content of other elements including $\mathrm{Al}, \mathrm{Si}$ and $\mathrm{Na}$ introduced by zeolite were also detected in ZAC.

As shown in Fig. 6, diffraction peaks of Na-faujasite and sanidine were displayed on the zeolite. There was no obvious diffraction peak on NAC in small-angle range $\left(2 \theta=1-10^{\circ}\right)$, the main peaks detected at $2 \theta$ of $26^{\circ}$ was characteristic to amorphous carbon. The characteristic peaks of zeolite were appeared on the XRD pattern of ZAC, which showed the effectiveness of material synthesis.

\section{Adsorption}

Kinetics studies. Three kinetic models were used to study the controlling step and the mechanism of pollutant adsorption on ZAC, which were Pseudo-First-Order (PFO), Pseudo-SecondOrder (PSO) and intra-particle diffusion model, respectively.

The PFO model is given as a linear equation: ${ }^{33}$

$$
\ln \left(q_{\mathrm{e}}-q_{t}\right)=\ln q_{\mathrm{e}}-k_{1} t
$$

where $k_{1}\left(\min ^{-1}\right)$ is the PFO rate constant, $q_{\mathrm{e}}\left(\mathrm{mg} \mathrm{g}^{-1}\right)$ and $q_{t}$ $\left(\mathrm{mg} \mathrm{g}^{-1}\right)$ are the adsorption capacity of the adsorbent at equilibrium and at time $t$, respectively. The slope and intercept of plot of $\ln \left(q_{\mathrm{e}}-q_{t}\right)$ versus $t$ were used to calculate the PFO rate constant at $25{ }^{\circ} \mathrm{C}$.

The PSO model is written as: ${ }^{34}$

$$
\frac{t}{q_{t}}=\frac{1}{k_{2} q_{\mathrm{e}}^{2}}+\frac{t}{q_{\mathrm{e}}}
$$

where $k_{2}\left(\mathrm{~g} \mathrm{mg}^{-1} \mathrm{~min}^{-1}\right)$ is the PSO rate constant. Fitting was carried out by plotting $t / q_{t}$ versus $t$ to calculate the PSO rate constant at $25{ }^{\circ} \mathrm{C}$.

The kinetic parameters and the correlation coefficients $\left(R^{2}\right)$ are presented in Table $2 . R^{2}$ value of PSO model (0.9993) was higher than the one of PFO model (0.9243), and the calculated adsorption capacity $\left(769.23 \mathrm{mg} \mathrm{g}^{-1}\right)$ was in good agreement with the experimental $q_{\mathrm{e}}$ (770.64 $\mathrm{mg} \mathrm{g}^{-1}$ ). PSO model was well fitted to the ZAC adsorption process. The PSO kinetic behavior suggested that the adsorption mechanism was the rate controlling step rather than the mass transfer from the solution 
Table 1 Porous characteristic of the produced adsorbents

\begin{tabular}{lcllc}
\hline Adsorbents & $S_{\text {BET }}\left(\mathrm{m}^{2} \mathrm{~g}^{-1}\right)$ & $V_{\text {tot }}\left(\mathrm{cm}^{3} \mathrm{~g}^{-1}\right)$ & $V_{\text {mes }}\left(\mathrm{cm}^{3} \mathrm{~g}^{-1}\right)$ & $V_{\text {mic }}\left(\mathrm{cm}^{3} \mathrm{~g}^{-1}\right)$ \\
\hline Zeolite (Z) & 77.21 & 0.6269 & 0.6254 & 0.0014 \\
ZAC (5:5) & 563.61 & 0.5959 & 0.5545 & 0.0414 \\
NAC & 1214.98 & 0.7950 & 0.7040 & 0.0910
\end{tabular}

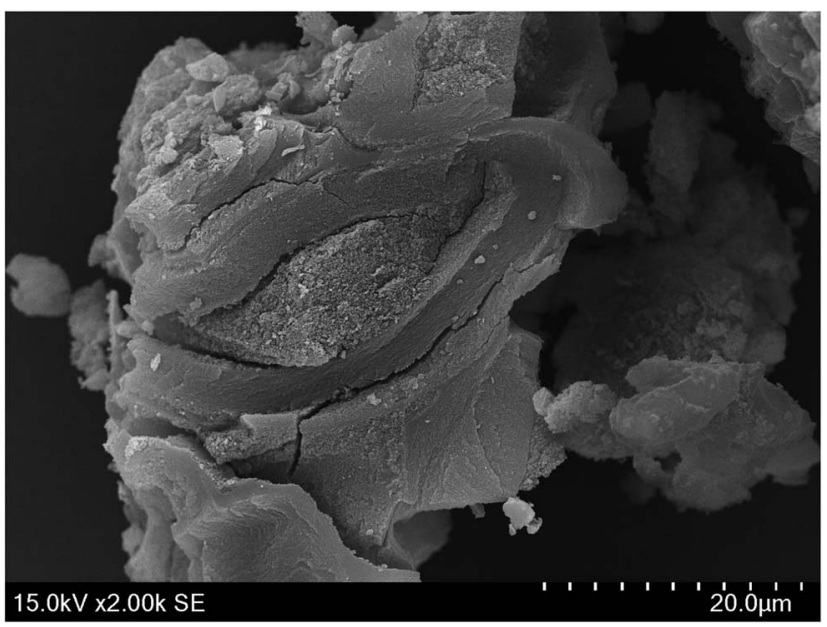

Fig. 5 SEM picture of ZAC.

to the adsorbent's surface, and the adsorption rate of COD on the composite ZAC did not depend on the initial COD concentration but the availability of the adsorption sites. ${ }^{24}$

The intra-particle diffusion model is also applied to explore the adsorption progress, which is represented by the following equation: $:^{35}$

$$
q_{t}=k_{\mathrm{id}} t^{1 / 2}+C
$$

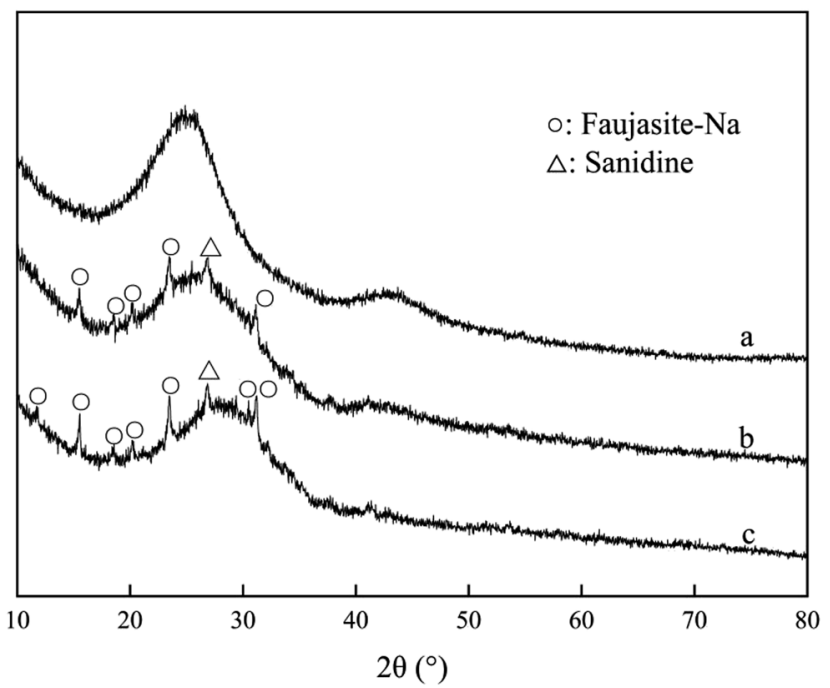

Fig. 6 XRD spectrum of three materials (a: NAC, b: ZAC, and c: zeolite Z).
Table 2 Kinetics parameters for the COD adsorption onto ZAC at $25^{\circ} \mathrm{C}$

\begin{tabular}{llc}
\hline Kinetic model & Parameters & Values \\
\hline & $q_{\mathrm{e}, \mathrm{exp}} / \mathrm{mg} \mathrm{g}^{-1}$ & 770.64 \\
Pseudo-first-order & $k_{1} \times 10^{-3} / \mathrm{min}^{-1}$ & 9.92 \\
& $q_{\mathrm{e}, \mathrm{cal}} / \mathrm{mg} \mathrm{g}^{-1}$ & 153.33 \\
& $R^{2}$ & 0.9243 \\
Pseudo-second-order & $k_{2} / \mathrm{g} \mathrm{mg}^{-1} \mathrm{~min}^{-1}$ & 0.0007 \\
& $q_{\mathrm{e}}, \mathrm{cal}^{-1} \mathrm{mg} \mathrm{g}^{-1}$ & 769.23 \\
Intra-particle diffusion & $R^{2}$ & 0.9993 \\
& $K_{\mathrm{id} 1} /\left(\mathrm{mg}\left(\mathrm{g} \mathrm{min}^{1 / 2}\right)^{-1}\right)$ & 24.68 \\
& $C_{1}$ & 585.36 \\
& $R_{1}{ }^{2}$ & 0.8138 \\
& $K_{\mathrm{id} 2} /\left(\mathrm{mg}\left(\mathrm{g} \mathrm{min}^{1 / 2}\right)^{-1}\right)$ & 8.14 \\
& $C_{2}$ & 662.69 \\
& $R_{2}{ }^{2}$ & 0.9921
\end{tabular}

where $k_{\text {id }}$ is the intra-particle diffusion rate constant. $C$ is a constant related to the boundary layer thickness. The slope and intercept of plot of $q_{t}$ versus $t$ (Fig. 7) were used to determine the $k_{\text {id }}$ and $C$.

As illustration by the intra-particle diffusion model: if the fitting plot gives a straight line, the adsorption process is impacted by an intra-particle diffusion; if this line passes through the origin, intra-particle diffusion is a rate determining step. ${ }^{24,36}$ As displayed in Fig. 7, the plots could be divided into two parts. Lines were straight but did not cross the origin, indicating that intra-particle diffusion was not the single ratedetermining step. The much larger slope of the first line proved that the COD removal rate by ZAC was high in the beginning, because of the instantaneous availability of large surface area and active sites. The gradual slope of the second line showed a slow adsorption rate due to concentration gradient decreasing and slower adsorbate diffusion. ${ }^{37}$

Adsorption isotherm. The adsorption isotherm indicates the distribution of adsorption molecules between the liquid phase and the solid phase when the adsorption process reaches an equilibrium state. Three isotherm models were employed to fit the experimental data and the results were showed in Table 3.

The Langmuir isotherm model is usually used to depict monomolecular layer adsorption on the active sites of the absorbent surface. It is expressed by the following equation: ${ }^{38}$

$$
q_{\mathrm{e}}=\frac{q_{\max } K_{\mathrm{L}} C_{\mathrm{e}}}{1+K_{\mathrm{L}} C_{\mathrm{e}}}
$$

where $q_{\max }\left(\mathrm{mg} \mathrm{g}^{-1}\right)$ is the maximum adsorption capacity of the adsorbent, $K_{\mathrm{L}}\left(\mathrm{L} \mathrm{mg}^{-1}\right)$ is the Langmuir constant related to the maximum adsorption capacity and adsorption energy. The essential characteristic of a Langmuir isotherm can be 


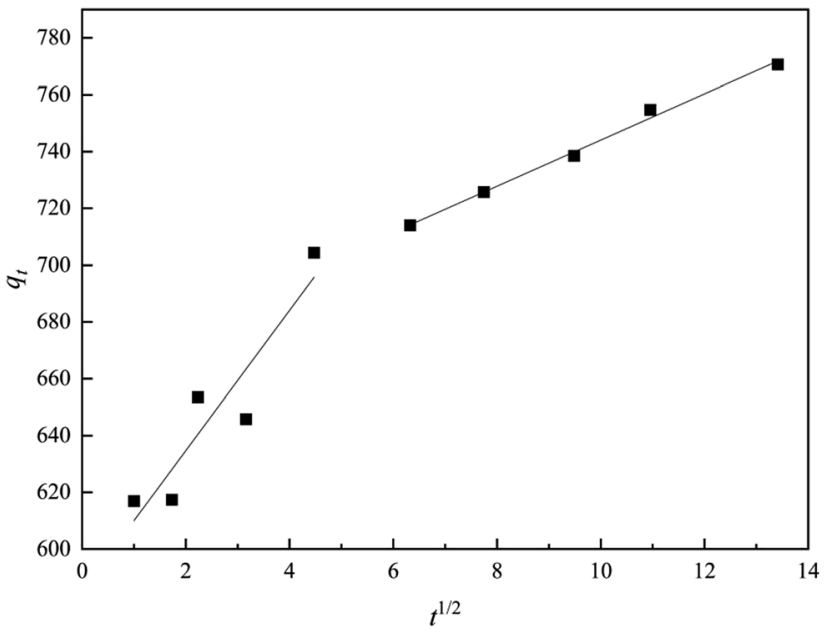

Fig. 7 Adsorption kinetics of COD adsorbed by ZAC with intra-particle diffusion model.

expressed on the basis of a dimensionless separation factor $R_{\mathrm{L}}$, which is defined as: $:^{2,39}$

$$
R_{\mathrm{L}}=\frac{1}{1+K_{\mathrm{L}} C_{0}}
$$

where $K_{\mathrm{L}}$ is the Langmuir constant and $C_{0}\left(\mathrm{mg} \mathrm{L}^{-1}\right)$ is the highest COD initial concentration. According to the value of $R_{\mathrm{L}}$, the isotherm can be expressed as unfavorable $\left(R_{\mathrm{L}}>1\right)$, linear $\left(R_{\mathrm{L}}\right.$ $=1)$, favorable $\left(0<R_{\mathrm{L}}<1\right)$ or irreversible $\left(R_{\mathrm{L}}=0\right)$.

The Freundlich isotherm assumes non-ideal adsorption taking place on a heterogeneous surface and adsorption energy decreasing logarithmically with adsorption capacity decreasing. It is given by the following empirical equation: ${ }^{40}$

$$
q_{\mathrm{e}}=K_{\mathrm{F}} C_{\mathrm{e}}^{1 / n}
$$

where $K_{\mathrm{F}}\left(\mathrm{mg} \mathrm{g}^{-1}\right)\left(\mathrm{L} \mathrm{mg}^{-1}\right)$ and $n$ are the Freundlich constants related to adsorption capacity and adsorption intensity, respectively.

The Temkin isotherm suggests a linear decrease of adsorption energy with adsorption capacity decreasing, which is similar to Freundlich model. ${ }^{41}$ It is usually applied as the following form:

$$
q_{\mathrm{e}}=B \ln A+B \ln C_{\mathrm{e}}
$$

where $B=R T / b, b$ is the Temkin constant related to heat of sorption $\left(\mathrm{J} \mathrm{mol}^{-1}\right), A$ is the Temkin isotherm constant $\left(\mathrm{L} \mathrm{g}^{-1}\right), R$ is the gas constant $\left(8.314 \mathrm{~J} \mathrm{~mol}^{-1} \mathrm{~K}^{-1}\right)$ and $T$ is the absolute temperature $(\mathrm{K})$.
As listed in Table 3 , the adsorption capacity $q_{\mathrm{e}}$ progressively increased with the equilibrium concentration of COD $\left(C_{\mathrm{e}}\right)$ in aqueous solution, showing that the equilibrium adsorption capacity was positively affected by the temperature. The highest $q_{\mathrm{e}}$ value (1109.75 $\mathrm{mg} \mathrm{g}^{-1}$ ) was observed in $25{ }^{\circ} \mathrm{C}$ for the initial COD concentration of $1633.33 \mathrm{mg} \mathrm{L}^{-1}$, which is well consistent with calculated value $q_{\max } 1139.81 \mathrm{mg} \mathrm{g}^{-1}$.

As listed in Table $3, R^{2}$ of the Langmuir isotherm is evidently higher than others, which means the Langmuir model is more applicable for the experimental data and the COD adsorption process onto composite ZAC is mono-layer adsorption. The value of $R_{\mathrm{L}}$ for adsorption of COD onto ZAC was 0.024, 0.022, 0.019 at $15{ }^{\circ} \mathrm{C}, 25{ }^{\circ} \mathrm{C}, 35{ }^{\circ} \mathrm{C}$, respectively. It indicated that the adsorption $n$ was favorable in most situations. Moreover, the Freundlich constant $n$ is a deviation measure. The value $n=$ 4.54 was greater than unity and showed that COD adsorption process by the composite ZAC was favorable. ${ }^{42}$

Thermodynamics. The effect of temperature on COD adsorption onto ZAC was studied in the temperature range of 15-35 ${ }^{\circ} \mathrm{C}$ and experimental data were explained by thermodynamic adsorption parameters, such as standard Gibbs free energy change $\left(\Delta G^{0}\right)$, enthalpy change $\left(\Delta H^{0}\right)$, entropy change $\left(\Delta S^{0}\right)$, using Gibbs-Helmholtz equation and Van't Hoff equations: $:^{24}$

$$
\Delta G^{0}=-R T \ln K_{\mathrm{D}}
$$

where $K_{\mathrm{D}}$ is the adsorption equilibrium constant, which can be calculated as follows:

$$
K_{\mathrm{D}}=\frac{q_{\mathrm{e}}}{C_{\mathrm{e}}}
$$

The relationship among $\Delta G^{0}, \Delta H^{0}$ and $\Delta S^{0}$ is expressed by:

$$
\Delta G^{0}=\Delta H^{0}-T \Delta S^{0}
$$

Based on (10) and (11), eqn (12) can be rearranged by following:

$$
\ln K_{\mathrm{D}}=\frac{\Delta S^{0}}{R}-\frac{\Delta H^{0}}{R T}
$$

where $T$ is the adsorption temperature $(\mathrm{K}), R$ is the universal gas constant $\left(8.314 \mathrm{~J} \mathrm{~mol}^{-1}\right)$. The values of $\Delta H^{0}$ and $\Delta S^{0}$ were determined from the intercept and slope of plot $\ln K_{\mathrm{D}}$ versus $1 / T$ (Table 4).

The negative values of $\Delta G^{0}$ revealed that the COD adsorption onto the composite ZAC was favorable and spontaneous. Moreover, the positive value $4.56 \mathrm{~kJ} \mathrm{~mol}^{-1}$ of $\Delta H^{0}$ demonstrated

Table 3 Langmuir, Freundlich, and Temkin isotherm parameters for the COD adsorption onto ZAC

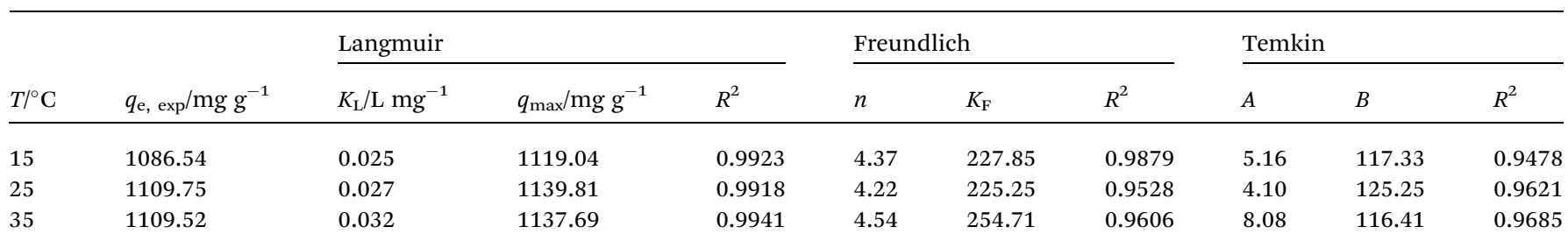


Table 4 Thermodynamics parameters for the COD adsorption onto ZAC at different temperatures

\begin{tabular}{llll}
\hline & COD adsorption & & \\
\cline { 2 - 4 }$T /^{\circ} \mathrm{C}$ & $\Delta G^{0} /\left(\mathrm{kJ} \mathrm{mol}^{-1)}\right.$ & $\Delta S^{0} /\left(\mathrm{J} \mathrm{mol}^{-1} \mathrm{~K}^{-1)}\right.$ & $\Delta H^{0} /\left(\mathrm{kJ} \mathrm{mol}^{-1}\right)$ \\
\hline 15 & -3.50 & 27.88 & 4.56 \\
25 & -3.67 & & \\
35 & -4.07 & &
\end{tabular}

that the adsorption process was endothermic and physisorption, ${ }^{43}$ which was in good agreement with the adsorption isotherm. The $\Delta S^{0}$ value was also positive $\left(27.88 \mathrm{~J} \mathrm{~mol}^{-1} \mathrm{~K}^{-1}\right)$, which represented the randomness increasing at the solid/ solution interface during the adsorption process.

\section{Conclusions}

The synthetic composite ZAC showed good adsorption capacity in simultaneous removal of COD and $\mathrm{NH}_{4}{ }^{+}-\mathrm{N}$. The effects of adhesives (CMC, PVA, and sodium silicate), molding pressure (2-10 MPa), and synthetic temperature $\left(100-300{ }^{\circ} \mathrm{C}\right)$ on ZAC production were studied and optimized. With addition of $15 \%$ CMC, mixed in a synthetic ratio of $5: 5$ (zeolite/NAC) by mass, extruded under $8 \mathrm{MPa}$ and heated at $200{ }^{\circ} \mathrm{C}$ for $1 \mathrm{~h}$, the produced composite ZAC had a maximum removal rate of $68 \%$ COD and $49 \% \mathrm{NH}_{4}{ }^{+}-\mathrm{N}$. The kinetics, equilibrium, and thermodynamics parameters for the adsorption process were investigated. The adsorption kinetics was well fitted the PSO kinetic model. In contrast to Freundlich and Temkin isotherm models, the equilibrium adsorption data were better depicted by Langmuir isotherm according to a higher $R^{2}$ value. The adsorption process of COD onto ZAC was endothermic, spontaneous and favorable on the thermodynamics analysis.

\section{Conflicts of interest}

There are no conflicts to declare.

\section{Acknowledgements}

We would like to acknowledge the funding support by National Science and Technology Major Project of the Ministry of Science and Technology of China (grant no. 2016ZX05017-005-008).

\section{References}

1 A. Jumasiah, T. G. Chuah, J. Gimbon, T. S. Y. Choong and I. Azni, Desalination, 2005, 186, 57-64.

2 A. A. Ahmad, B. H. Hameed and N. Aziz, J. Hazard. Mater., 2007, 141, 70-76.

3 K. A. Krishnan and T. S. Anirudhan, Ind. Eng. Chem. Res., 2002, 41, 5085-5093.

4 A. Oehmen, P. C. Lemos, G. Carvalho, Z. Yuan, J. Keller, L. L. Blackall and M. A. M. Reis, Water Res., 2007, 41, 2271-2300.
5 P. Hadi, M. Xu, C. Ning, C. S. K. Lin and G. Mckay, Chem. Eng. J., 2015, 260, 895-906.

6 Y. Zhang, F. Yu, W. Cheng, J. Wang and J. Ma, Journal of Chemistry, 2017, 2017, 9.

7 Z. Hong, L. Han, H. Ma, Z. Yan, H. Zhang, D. Liu and S. Liang, J. Hazard. Mater., 2008, 158, 577-584.

8 D. J. Randall and T. K. Tsui, Mar. Pollut. Bull., 2002, 45, 1723.

9 Y. Q. Liu, Y. P. Moy and J. H. Tay, Enzyme Microb. Technol., 2007, 42, 23-28.

10 M. S. Lucas and J. A. Peres, J. Hazard. Mater., 2009, 168, 1253-1259.

11 P. C. C. Faria, J. J. M. Órfão and M. F. R. Pereira, Appl. Catal., $B, 2009,88,341-350$.

12 S. He, J. Li, J. Xu and L. Mo, BioResources, 2016, 11, 83968408.

13 M. Altomare, G. L. Chiarello, A. Costa, M. Guarino and E. Selli, Chem. Eng. J., 2012, 191, 394-401.

14 M. Hasan, A. L. Ahmad and B. H. Hameed, Chem. Eng. J., 2008, 136, 164-172.

15 M. G. Vaz, A. G. B. Pereira, A. R. Fajardo, A. C. N. Azevedo and F. H. A. Rodrigues, Water, Air, Soil Pollut., 2017, 228, 14.

16 H. Huang, X. Xiao, Y. Bo and L. Yang, J. Hazard. Mater., 2010, 175, 247-252.

17 D. Karadag, Y. Koc, M. Turan and B. Armagan, J. Hazard. Mater., 2006, 136, 604-609.

18 D. Mohan, K. P. Singh, A. Gurdeep Singh and K. Kumar, Ind. Eng. Chem. Res., 2002, 41, 3688-3695.

19 S. Rio, C. Faur-Brasquet, L. L. Coq and P. L. Cloirec, Environ. Sci. Technol., 2005, 39, 4249-4257.

20 B. Royer, N. F. Cardoso, E. C. Lima, J. C. Vaghetti, N. M. Simon, T. Calvete and R. C. Veses, J. Hazard. Mater., 2009, 164, 1213-1222.

21 P. K. Malik, J. Hazard. Mater., 2004, 113, 81-88.

22 B. H. Hameed and F. B. M. Daud, Chem. Eng. J., 2008, 139, 48-55.

23 E. S. Abechi, C. E. Gimba, A. Uzairu and J. A. Kagbu, Arch. Appl. Sci. Res., 2011, 46, 154-164.

24 W. A. Khanday, F. Marrakchi, M. Asif and B. H. Hameed, J. Taiwan Inst. Chem. Eng., 2017, 70, 32-41.

25 E. L. K. Mui, W. H. Cheung, M. Valix and G. Mckay, Microporous Mesoporous Mater., 2010, 130, 287-294.

26 B. H. Hameed, A. T. Din and A. L. Ahmad, J. Hazard. Mater., 2007, 141, 819-825.

27 M. Wang, R. Xie, Y. Chen, X. Pu, W. Jiang and L. Yao, Bioresour. Technol., 2018, 268, 726-732.

28 H. Azhar Abdul, A. Hamidi Abdul, J. Megat Azmi Megat and A. Kamar Shah, Desalination, 2010, 262, 31-35.

29 D. Nguyen-Thanh and T. J. Bandosz, Carbon, 2005, 43, 359367.

30 A. A. Halim, H. A. Aziz, M. A. M. Johari, K. S. Ariffin and M. N. Adlan, J. Hazard. Mater., 2010, 175, 960-964.

31 R. Leyva-Ramos, G. Aguilar-Armenta, L. V. GonzalezGutierrez, R. M. Guerrero-Coronado and J. MendozaBarron, J. Chem. Technol. Biotechnol., 2010, 79, 651-657.

32 Y. Wang, Y. Kmiya and T. Okuhara, Water Res., 2007, 41, 269276. 
33 S. K. Lagergren, K. Sven. Vetenskapsakad. Handl., 1898, 24, 139.

34 Y. S. Ho, Water Res., 2006, 40, 119-125.

35 W. J. Weber and J. C. Morris, J. Sanit. Eng. Div., Am. Soc. Civ. Eng., 1963, 89, 31-60.

36 H. Y. Zhu, Y. Q. Fu, R. Jiang, J. H. Jiang, L. Xiao, G. M. Zeng, S. L. Zhao and Y. Wang, Chem. Eng. J., 2011, 173, 494-502.

37 Y. Li, Q. Du, T. Liu, J. Sun, Y. Wang, S. Wu, Z. Wang, Y. Xia and L. Xia, Carbohydr. Polym., 2013, 95, 501-507.

38 I. Langmuir, J. Chem. Phys., 1918, 40, 1361-1403.
39 G. Mckay, H. S. Blair and J. R. Gardner, J. Appl. Polym. Sci., 2010, 29, 1499-1514.

40 H. F. M. Freundlich, Z. Phys. Chem., 1906, 57, 385-470.

41 R. D. Johnson and F. H. Arnold, Biochim. Biophys. Acta, 1995, 1247, 293-297.

42 A. S. Özcan, B. Erdem and A. Özcan, Colloids Surf., A, 2005, 266, 73-81.

43 W. P. Cheng, W. Gao, X. Cui, J. H. Ma and R. F. Li, J. Taiwan Inst. Chem. Eng., 2016, 62, 192-198. 